\title{
Mal de Arquivo: a dinâmica do arquivo na Arte Contemporânea
}

\author{
Silvana Macêdo*
}

\section{Resumo:}

A proposta deste texto é explorar o impacto da idéia de arquivo na arte contemporânea. Parte-se da perspectiva de Jacques Derrida sobre o conceito de arquivo, em "Mal de Arquivo - Uma impressão freudiana", no qual Derrida explora o duplo sentido da raiz da palavra arquivo, como origem e comando ou poder de uma autoridade. Ao relacionar a noção de arquivo com a memória (pessoal e histórica), o autor argumenta que há uma constante tensão entre a manutenção e repressão (consciente ou inconsciente) da memória. O mal de arquivo estaria ligado à pulsão de morte, ao apagamento da memória, cujas conseqüências podem ser psíquicas, sociais e políticas. Com esse entendimento, identificamos a idéia de arquivo como um procedimento central nas práticas artísticas contemporâneas. Diversos artistas desenvolvem projetos em torno de noções de falsificação de arquivos; partem da apropriação de arquivos históricos; ou incorporam metodologias científicas em seus processos poéticos, dando origem a arquivos fictícios e estranhas taxionomias.

\section{Palavras-chave:}

Arquivo; arte contemporânea; memória; fotografia; Derrida

\section{Mal de Arquivo}

A proposta deste texto é apontar alguns caminhos para se compreender o papel da idéia de arquivo na construção de projetos artísticos contemporâneos. Iniciamos com a definição de arquivo pelo dicionário Aurélio:

s.m. 1. Conjunto de documentos manuscritos, gráficos, fotográficos, etc., recebidos ou produzidos oficialmente por uma entidade ou por seus funcionários, e destinados a permanecer sob custódia dessa entidade ou funcionários. 2. Lugar onde se recolhem e guardam estes documentos.

Já nesta definição de dicionário pode-se observar o duplo aspecto do conceito de arquivo explorado por Derrida em seu texto Mal de Arquivo - Uma impressão freudiana $(1994,2001) .{ }^{1}$ Percebe-se aqui a presença do desejo de se preservar a memória pelo arquivamento de registros, e um sujeito/instituição arquivadora,

\footnotetext{
* PhD Fine Arts, professora da UDESC.

1 "Mal de Arquivo - Uma impressão freudiana" foi uma conferência de Derrida pronunciada em Londres, no dia 5 de junho de 1994, no colóquio internacional "Memória, a questão dos arquivos", organizado por iniciativa de René Major e Elizabeth Roudinesco e patrocinada pela Sociedade Internacional de História da Psiquiatria e da Psicanálise, do Museu Freud e do Instituto de Arte Courtauld.
} 
com o poder de decidir o que entra e o que fica fora do arquivo, e que também zela pelo acervo reunido. Estas operações não se dão de maneira ingênua ou neutra, pois a própria constituição de um arquivo gera um poder sobre o documento, sobre sua detenção, retenção ou interpretação, como explora Derrida neste texto.

Em "Mal de Arquivo", Derrida inicia investigando o duplo sentido da raiz da palavra arquivo, em grego arkhê, que significa tanto começo (origem/autenticidade), quanto comando (autoridade/poder):

De certa maneira, o vocábulo (arquivo) remete bastante bem, como temos razões de acreditar, ao arkhê no sentido físico, histórico ou ontológico; isto é, ao originário, ao primeiro, ao principal, ao primitivo em suma, ao começo. Porém, ainda mais, ou antes ainda, "arquivo" remete ao arkhê no sentido nomológico, ao arkhê do comando. (DERRIDA, 2001, p. 12)

O sentido nomológico de que fala Derrida vem do termo arkheîon, que em grego refere-se à residência dos magistrados superiores, os arcontes, aqueles que comandavam, que tinham poder político, podendo fazer ou representar a lei. Portanto este termo também se refere ao lugar onde documentos eram guardados, ganhando o poder de interpretá-los, como argumenta Derrida:

Os arcontes foram os seus primeiros guardiões. Não eram responsáveis apenas pela segurança física do depósito e do suporte. Cabiam-Ihes também o direito e a competência hermenêuticos. Tinham o poder de interpretar os arquivos. Depositados sob a guarda desses arcontes, estes documentos diziam, de fato, a lei: eles evocavam a lei e convocavam à lei. (Idem, p. 12-13)

Derrida continua nesta análise do poder arcôntico, com suas atribuições de unificação, identificação, classificação e consignação (reunir signos), evidenciando como estes processos podem servir tanto para abrigar quanto para dissimular (Ibid., p. 13), de acordo com os interesses de quem detém o poder sobre o arquivo. Derrida evidencia desta forma, que a constante tensão entre a manutenção e repressão (consciente ou inconsciente) da memória decorre desta relação entre o poder e o arquivo.

Mais adiante, Derrida busca no conceito freudiano de pulsão de morte, suporte para as dissimulações, repressões e destruição do arquivo pelo poder, que pode ser aplicado tanto à memória pessoal quanto a nível histórico. Observa que a pulsão de morte, de acordo com Freud, trabalha sempre em silêncio, "não deixa nunca nenhum arquivo que the seja próprio... ela trabalha para destruir o arquivo: com a condição de apagar mas também com vistas de apagar seus próprios traços." (Ibid., p. 21). Portanto a vocação da pulsão de morte tem este caráter destruidor de maneira sutil e silenciosa.

Como a pulsão de morte aniquila a memória, o arquivo destruído pela pulsão se encontrará reprimido justamente no lugar da falta estrutural da memória. Daí Derrida elabora seu conceito de "mal de arquivo": "A pulsão de morte não é um 
princípio. Ela ameaça de fato todo o principado, todo primado arcôntico, todo desejo de arquivo. É a isto que mais tarde chamaremos de mal de arquivo" (Ibid., p. 23).

Portanto, o mal de arquivo está ligado à pulsão de morte, ao apagamento da memória, ao esquecimento, cujas conseqüências podem ser psíquicas, no caso de memória individual, ou sociais e políticas, no caso da memória histórica.

Há ainda um outro aspecto que decorre da repressão da memória, a busca dos arquivos perdidos. Derrida fala desta busca quando discorre sobre a diferença entre estar com mal de arquivo e mal de arquivo (esquecimento):

...estar com mal de arquivo, pode significar outra coisa que não sofrer de um mal, de uma perturbação ou disso que o nome "mal" poderia nomear. É arder de paixão. É não ter sossego, é incessantemente, interminavelmente procurar o arquivo onde ele se esconde. É correr atrás dele ali onde, mesmo se há bastante, alguma coisa nele se anarquiva. É dirigir-se a ele com um desejo compulsivo, repetitivo e nostálgico, um desejo irreprimível de retorno à origem, uma dor da pátria, uma saudade de casa, uma nostalgia do retorno ao lugar mais arcaico do começo absoluto. Nenhum desejo, nenhuma paixão, nenhuma pulsão, nenhuma compulsão, nem compulsão de repetição, nenhum "mal-de", nenhuma febre, surgirá para aquele que, de um modo ou outro, não está já com mal de arquivo. (Ibid., p. 118-119)

Trago estas considerações filosóficas em torno do arquivo elaboradas por Derrida para lançar uma luz sobre as dinâmicas que se pode observar em diversos projetos artísticos contemporâneos. Na parte seguinte deste texto buscarei identificar como a idéia de arquivo passou a ser um procedimento central nas práticas artísticas contemporâneas.

\section{A Noção de Arquivo na Arte Contemporânea}

Atualmente há uma grande diversidade de artistas trabalhando com as mais diversas mídias em torno de noções de arquivo, como argumentam importantes críticos e curadores no cenário internacional, entre eles, Hal Foster em seu em seu artigo "An Archival Impulse" (2004), e Okwui Enwezor, no seu texto de abertura do catálogo da exposição "Archive Fever: uses of document in contemporary art", no International Center of Photography, New York, 2008. Diante da vasta amplitude que este tema abarca, não seria possível abordar todos os artistas e discussões críticas deste cenário neste breve texto. Para dar conta pelo menos parcialmente do objetivo de tratar da questão do arquivo na arte contemporânea, buscarei focar na produção de alguns dos artistas que abordam especificamente a noção de arquivo em seus trabalhos em fotografia.

Talvez pudéssemos pensar que qualquer série de trabalhos de artistas poderia ser pensada em termos de arquivo, pertencendo ao "grande arquivo da arte". Mas, aqui, me aterei a trabalhos que lidam mais diretamente com a questão do registro da memória ou seu apagamento, com as questões de origem e autoridade que emergem do arquivo expostas acima por Derrida. Poder-se-ia também abordar 
esta questão com um foco no registro de ações artísticas efêmeras, como as performances e happenings, que geraram inúmeros arquivos de grande importância para a arte contemporânea. Tais arquivos assumem atualmente um papel que extrapola o meramente documental, funcionando como fonte primária de acesso a performances que foram feitas especialmente para a câmera, como os trabalhos de Vitor Acconci, Sophie Calle, Bruce Nauman, Ana Mendieta, Hamish Fulton, Richard Long, Gabriel Orozco, entre muitos outros. Entretanto, meu foco não será sobre estes trabalhos, deixando este assunto para uma outra oportunidade, para que eu possa me ater aqui aos trabalhos que apresentam uma outra dinâmica, que também são fundamentadas na idéia de arquivo como área principal de significação.

Inicialmente falarei dos artistas que se apropriam de arquivos existentes para a construção de seus projetos, acessando tanto arquivos históricos quanto pessoais. Em seguida, apresentarei alguns trabalhos de artistas que criam falsos arquivos; e finalmente aqueles que constroem arquivos pessoais ou sociais assumindo a metodologia de arquivamento em seu processo criativo.

\section{Apropriação de arquivos históricos e pessoais: Christian Boltanski, Ro- sângela Rennó, Rosana Paulino}

\subsection{Christian Boltanski}

A série de instalações fotográficas do artista francês Christian Boltanski (1944) das décadas de 1980 e 90 têm como tema central a identidade, morte, a memória e o esquecimento. Em diversas instalações deste período, como em Altar para Chases High School (Autel Chases), 1987, Monumento Canadá, 1988, Monument (Odessa), 1989-2003, e Réserve des Suisses morts, 1990, há um desejo de se evidenciar a perda de memória de indivíduos judeus, que possivelmente foram vítimas do Holocausto.

O crítico Okwui Enwezor comenta a maneira como Boltanski manipula arquivos fotográficos criando impressões distintas, nos fazendo suspeitar do poder da fotografia em atuar como receptáculo para a memória:

Por aproximadamente quarenta anos, Boltanski coloca questionamentos conceituais e filosóficos sobre a estabilidade do arquivo como meio pelo qual podemos conhecer e entender o passado, não de maneira a entrar na lógica de relembrar mas de explorar e expor como as imagens fotográficas perturbam a lembrança, e na sua inconsistência perfuram a membrana da memória pública e privada. Em diversos arranjos aos quais estão sujeitas, Boltanski frequentemente trata documentos fotográficos de maneiras contraditórias: às vezes são colecionadas em uma estrutura linear formando uma narrativa coerente, ou podem ser transformadas em unidades individualizadas fetichizadas, sobre as quais a tenra luz de uma luminária (spotlight) é fixada, conferindo a elas um caráter quase devocional, em uma armadura de configurações sentimentais que, marcantemente, são construídas para evocar santuários. (Enwezor, 2008, p.31) 


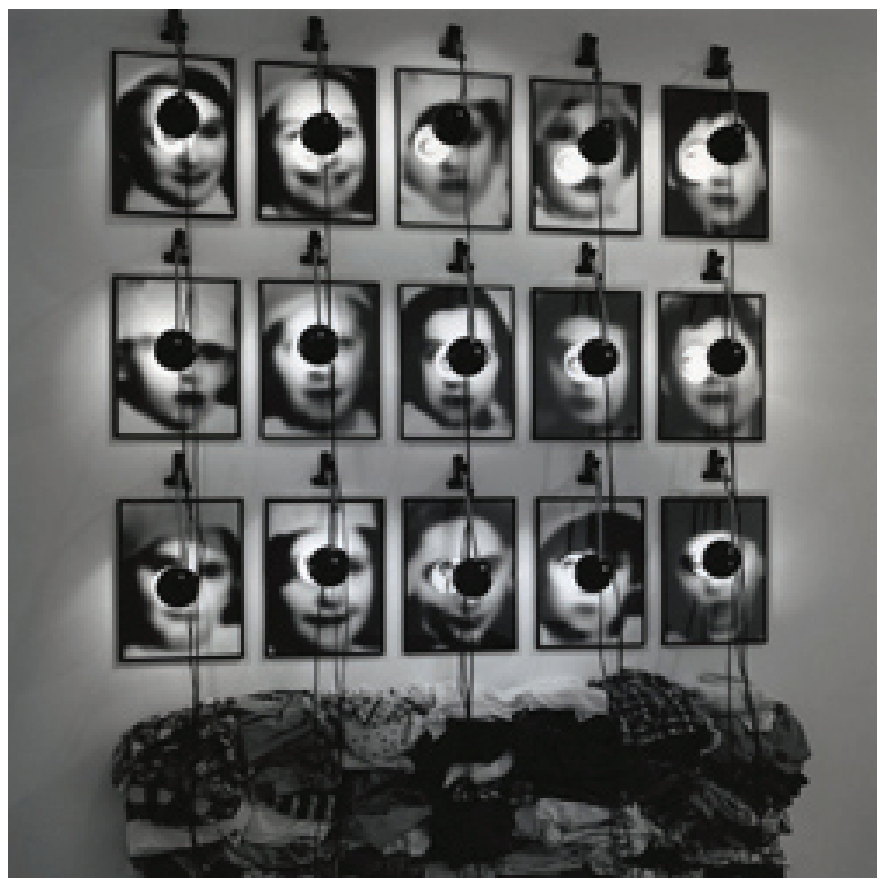

Ilust.1. Christian Boltanski, Monumento Canadá, 1988

Esta atmosfera de santuário pode ser sentida na instalação fotográfica Monumento Canadá (1988), composta por fotografias de retratos de crianças de um arquivo de uma escola judia. Na instalação, a série de fotografias em preto e branco de rostos de crianças, são dispostas com luminárias parecidas com luzes em salas de interrogatório (Ilust.1), dificultando a identificação dos retratados. As imagens dos rostos adquirem um aspecto de vulnerabilidade a mais sob este tipo de luz. Somado a isso, a instalação inclui roupas cuidadosamente dobradas e colocadas no chão. Aqui, tanto a fotografia quando as peças de vestuário funcionam como relíquias, remetendo a uma polaridade de presença e ausência.

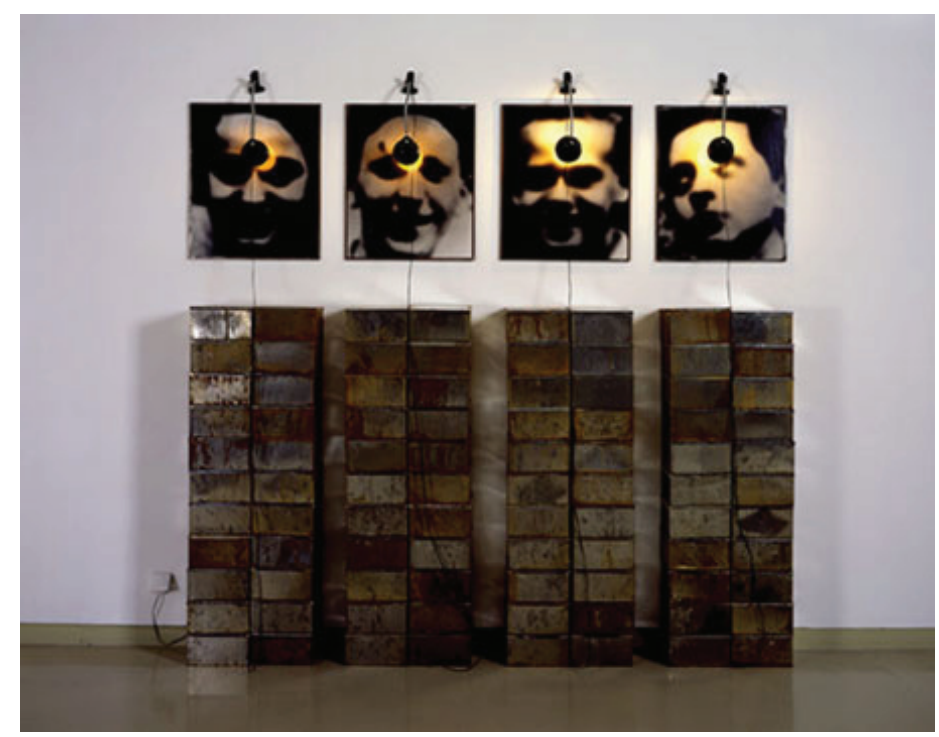

Ilust. 2. Christian Boltanski, Chases High School (Autel Chases), 1987 
Morte, memória e infância são temas recorrentes em seu trabalho. Altar para os alunos da Chases High School também é baseado em fotografias encontradas de graduandos de uma escola judia em Viena em 1931. Neste projeto, Boltanski também re-fotografou o rosto de cada estudante, aumentando suas dimensões até as imagens perderem detalhes. Logo abaixo das fotografias, foram montadas pilhas de latas de alumínio remetendo à idéia de possíveis receptáculos de pertences, relíquias ou memórias de cada vítima.

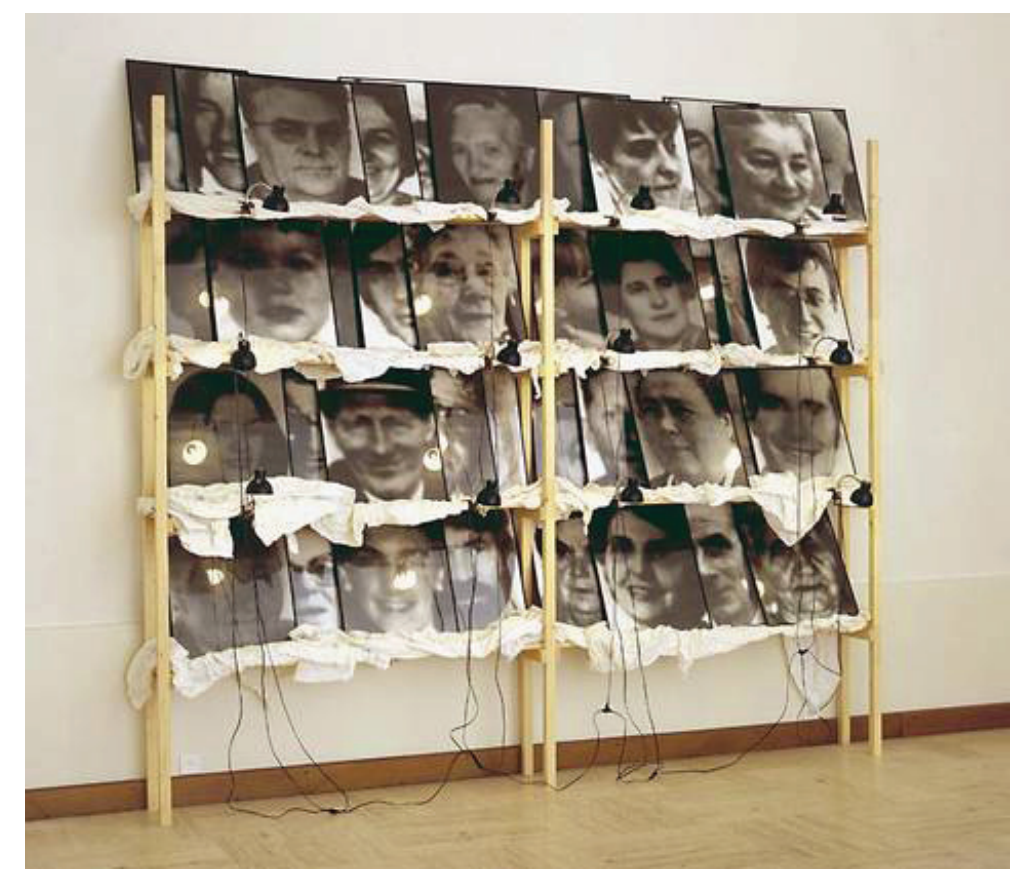

Ilust.3. Christian Boltanski, Réserve des Suisses morts, 1990

Em Réserve des Suisses morts, 1990, o artista parece buscar resgatar memórias coletivas anônimas, trabalhando também a partir de imagens de arquivos existentes. Boltanski em todas estas séries de trabalhos, não fotografou pessoas diretamente, mas fotografou fotografias de arquivos, num processo de perda de detalhes, no qual a imagem sofreu um apagamento parcial.

Considerando esta série de trabalhos, poderíamos argumentar que Boltanski estaria justamente explorando a dinâmica daquilo que Derrida denominou mal de arquivo. Ao mesmo tempo que Boltanski busca obsessivamente remexer na memória histórica de um passado traumático, talvez com a intenção de restaurar um arquivo do esquecimento, há ao mesmo tempo um impulso de destruição do mesmo. A violência e a destruição da pulsão de morte manifestam-se na perda das feições individuais dos retratados. O que vemos é um acúmulo de vultos pouco nítidos, em preto e branco, parecendo mais máscaras melancólicas do que rostos. A perda da individualidade de cada pessoa retratada, este apagamento da imagem, nos remete à violência histórica a qual sofreram, sendo esta dor impossível de ser representada diretamente, mas que reverberam no vazio da superfície impenetrável de cada imagem. 


\subsection{Rosângela Rennó}

Este processo de escavar novos sentidos de arquivos existentes também faz parte da metodologia de trabalho da artista brasileira Rosângela Rennó, que em diversos projetos ressignifica imagens preexistentes. Negando-se a fotografar, Rennó apropria-se de imagens recolhidas em álbuns e arquivos fotográficos de família, de jornais, revistas, arquivos oficiais e fotografias de autores desconhecidos. Rennó fala de sua postura de encontrar novos sentidos em material descartado:

Sempre me preocupei com o uso social da imagem. Interesso-me pela produção vernacular, desprovida da roupagem estética, que já é uma espécie de "margem" da fotografia. Gosto de lidar com esse material, porque me fala da vida cotidiana, do indivíduo e do ser humano. Acredito que esse tipo de imagem conta muito mais sobre a humanidade do que a chamada fotografia de autor. A idéia da margem nos meus trabalhos corresponde ao que quase pula para fora do circuito dos objetos. O que quase vai para o lixo. Interesso-me por esse material pois ele me leva a pensar em que medida posso determinar que uma coisa não serve para absolutamente mais nada. Trata-se de uma questão de atribuição de valor e meu trabalho sempre começa pelo questionamento da atribuição de valor. Em fotografia, pode-se falar de valor estético, valor documental, valor simbólico, valor sentimental, e por aí vai... então, quando se destinou uma imagem ao lixo, significa que ela perdeu muita coisa. ${ }^{2}$

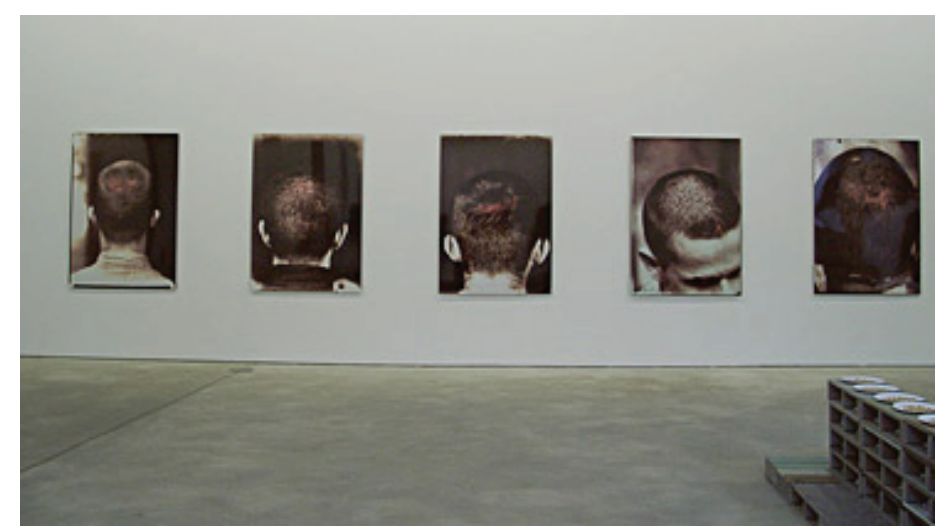

Ilust.4. Rosangela Rennó, Vulgo, 1998

Em inúmeras séries Rennó trabalha com imagens de fotógrafos desconhecidos ou amadores, cujo significado melancolicamente se esvaiu, sendo aqui a morte do sentido das imagens descartadas a área de interesse da artista. Há também séries em que a ligação entre imagem e morte é mais explícita, por exemplo, em: Duas lições de realismo fantástico, 1991, Imemorial, 1994, na série cicatriz, 1997 e vulgo, 1998, entre muitas outras. A pulsão de morte, o mal de arquivo, o esquecimento parece ser também o mecanismo em operação no processo fotográfico de Rennó, de maneira similar ao de Boltanski. Sendo que a temática principal de Rennó concentra-se muitas vezes, mas não sempre, na tragédia social brasileira (ela já afirmou que deseja retratar os vencidos ao invés dos vencedores). Rennó, 
parece querer resgatar um sentido aos retratos descartados, mas ao fazê-lo parece apagá-los mais ainda, esvaziá-los totalmente de seu sentido original num gesto claramente alegórico no sentido benjaminiano. Na re-contextualização da imagem percebemos uma irremediável perda de identidade do indivíduo retratado, emergindo talvez uma massa de pessoas, um retrato social do Brasil anônimo.

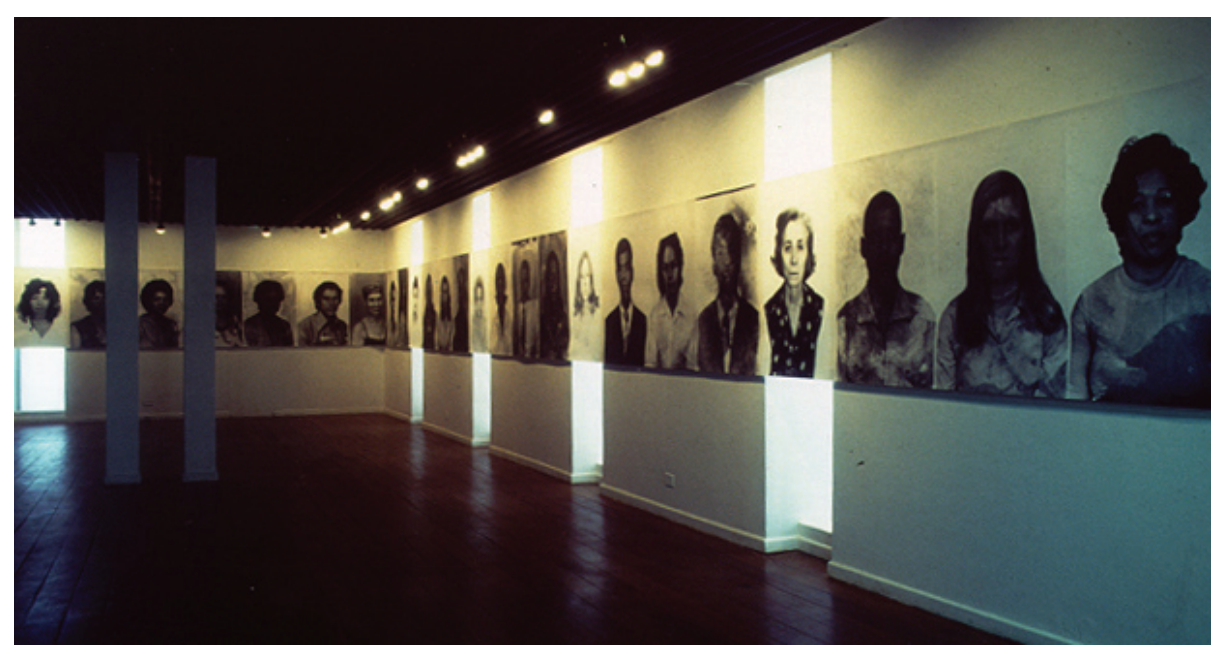

Ilust.5. Rosangela Rennó, Duas lições de realismo fantástico, 1991

O crítico Paulo Herkenhoff observa este apagamento da memória individual ao se referir à instalação Realismo Fantástico (1991/94), constituída por apropriação de fotos 3x4 de anônimos:

A nova imagem construída por Rosangela Rennó explicita uma anulação de milhares de imagens por sua repetição, banalidade e acumulação, e nesse esforço parece se esvair toda significação como um enfileiramento de retratos sem alma. O arquivo, a ficha, o formato $3 \times 4$, a convenção são agentes desse oblívio no campo social. (HERKENHOFF apud RENNÓ, 1998, p.153)

\subsection{Rosana Paulino}
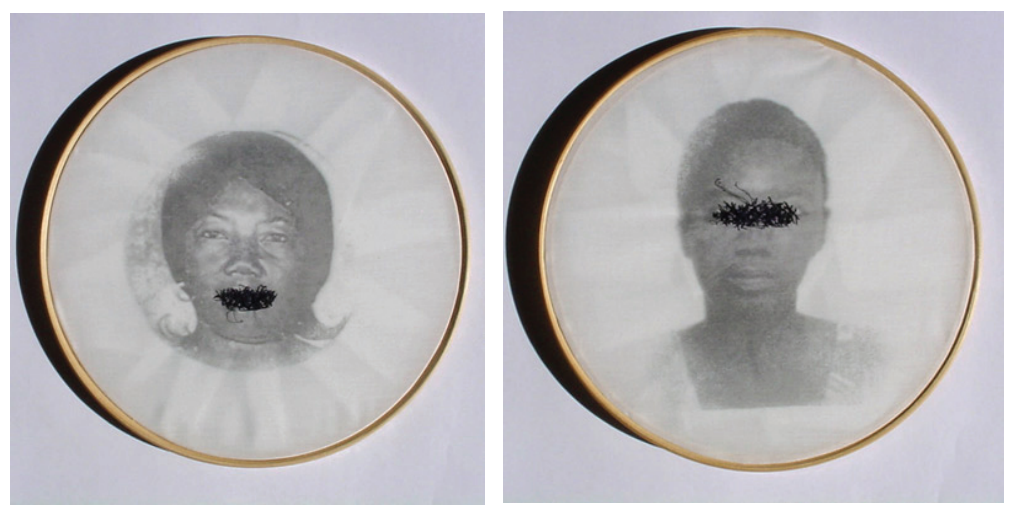

Ilust.6. Rosana Paulino, Bastidores, 1997

Já a artista Rosana Paulino, em sua belíssima série Bastidores (1997) de retratos 
de família, busca em seus arquivos familiares explorar questões étnicas e de gênero. Aqui o aspecto autobiográfico dá uma grande força ao trabalho. A violência do gesto contra o suporte, o bordado sobre a imagem fotográfica impressa no tecido, nos remete a uma violência psicológica sofrida por muitas gerações de mulheres negras no Brasil, no caso, pelas familiares da artista. O silêncio das agressões muitas vezes reprimidas emerge das memórias (conscientes e inconscientes) nas potentes imagens de Paulino.

O bordado, uma atividade tradicionalmente feminina, aparece obliterando os olhos ou boca das mulheres retratadas. Este procedimento sugere que a vida feminina restrita ao âmbito doméstico causaria um processo de mutilação social, um estreitamento na visão e abafamento da voz da mulher sob a opressão patriarcal. O título da série também é sugestivo, pois muitas vezes o trabalho das mulheres permanece nos "bastidores", apesar de fundamental, frequentemente passa despercebido, sem o reconhecimento público, ao contrário de agentes (masculinos em sua maioria) que se mostram e se expressam abertamente no "palco" social.

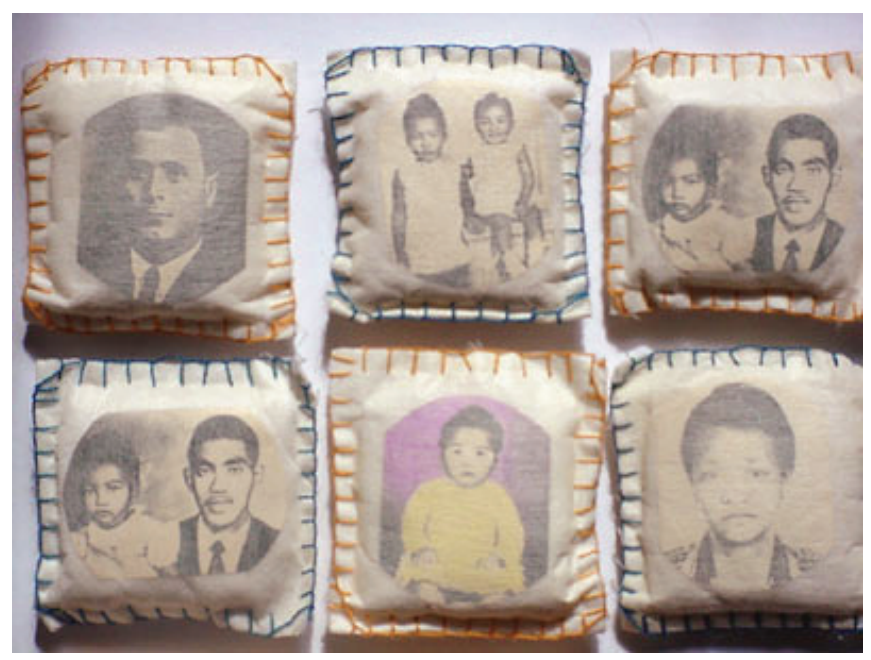

Ilust.7. Rosana Paulino, Parede da Memória, 1994

Pode-se dizer desta atitude de Paulino, que a mesma esteja com mal de arquivo, no sentido que Derrida descreveu, tomada por uma paixão, um desejo de procurar o arquivo onde ele se esconde, "um desejo irreprimível de retorno à origem", buscando nesta origem seus arquivos identitários, as dores de gerações passadas, e também a grande força e beleza que reside nestes arquivos profundos e misteriosos da memória.

\section{Criação de falsos arquivos: Joan Fontcuberta}

Já o artista catalão Joan Fontcuberta trabalha com a idéia de arquivo num outro sentido, com a finalidade de desconstruir o discurso da fotografia como evidência do real. Com esta intenção, trabalhou na série Fauna (1989), em colaboração com o fotógrafo Pere Formiguera, construindo imagens fotográficas sem nenhuma manipulação digital, para criar arquivos científicos fictícios com grande ironia e humor, desmascarando assim a autoridade do discurso cientificista e o papel da 
fotografia como prova da verdade.

Fauna (1989) se configurou como uma instalação multidisciplinar centrada em um bestiário fantástico: fotografías, radiografías, desenhos de campo, mapas de viagens, fichas zoológicas, textos, registros sonoros, vídeos, animais dissecados, instrumental de laboratório, correspondência, etc. Para articular a proposta, Fontcuberta cria a história de um naturalista alemão, o professor Peter Ameisenhaufen e seu ajudante, Hans von Kubert. ${ }^{3}$

Os artistas relatam a descoberta dos arquivos do zoólogo Dr. Peter Ameisenhaufen, nascido em 1895 e que desapareceu misteriosamente em 1955. Ameisenhaufen teria catalogado um grande número de animais estranhos, como por exemplo, o Ceropithecus icarocornu que se parece com um macaco alado com um chifre de unicórnio, e a Solenoglypha polipodida que parece uma cobra com 12 patas.

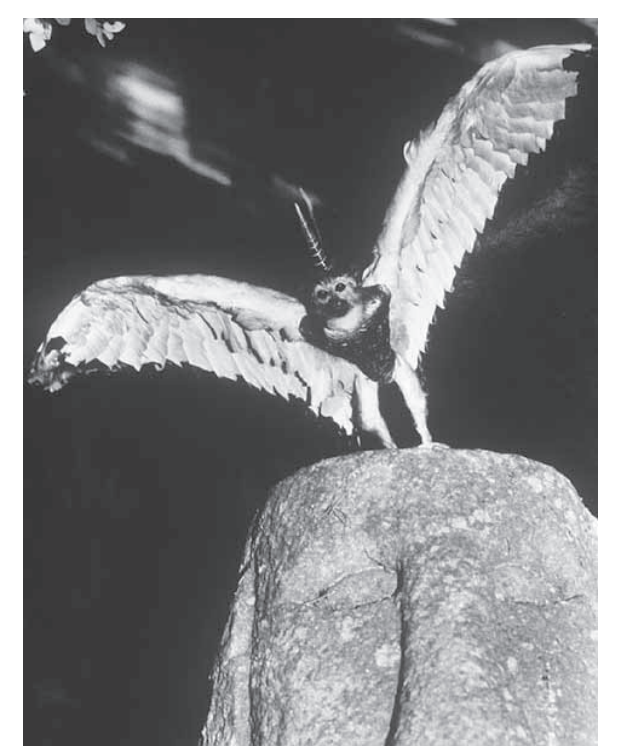

Ilust. 8. Joan Fontcuberta, Ceropithecus icarocornu, da série Fauna, 1989

Além de bem humorados estes trabalhos, há um forte ceticismo diante de discursos autoritários subjacentes na postura de Fontcuberta, que, segundo o autor, é conseqüência direta da propaganda ideológica no período da ditadura de Franco na Espanha. A criação de falsos arquivos pelo poder de autoridades ilegítimas, bem como a supressão e manipulação de arquivos para fins escusos por poderes militares são o exemplo mais direto da pulsão de morte e destruição do qual nos fala Derrida no mal de arquivo, ou seja, o aniquilamento literal de arquivos, memórias e pessoas.

\section{Criação de arquivos pessoais e urbanos: Susan Hiller, Nara Milioli e asikainen\&macêdo}

${ }^{3} \mathrm{O}$ trabalho Fauna está on-line, disponível em: http://zonezero.com/EXPOSICIONES/fotografos/fontcuberta/pg1.html, acesso em 06/12/2009. 


\subsection{Susan Hiller}

A criação de arquivos pessoais em trabalhos contemporâneos é abundante e como exemplo trago aqui a instalação de Susan Hiller, intitulada From the Freud Museum (do museu de Freud) 1991-97, feita originalmente para este museu, mas depois mostrada em outros espaços. Segundo Hiller, este trabalho evoca as caixas e gavetas de um museu antropológico, apresentando uma coleção heterogênea de imagens e objetos de sua coleção pessoal, organizadas em caixas, devidamente etiquetadas, como se fossem objetos de alguma importância histórica. ${ }^{4} \mathrm{~A}$ artista fala do trabalho: "em um nível minha instalação-vitrine é uma coleção de coisas que evocam pontos históricos e culturais de derrapagem - psíquica, étnica, sexual, e perturbações políticas" (Hiller, 2000).

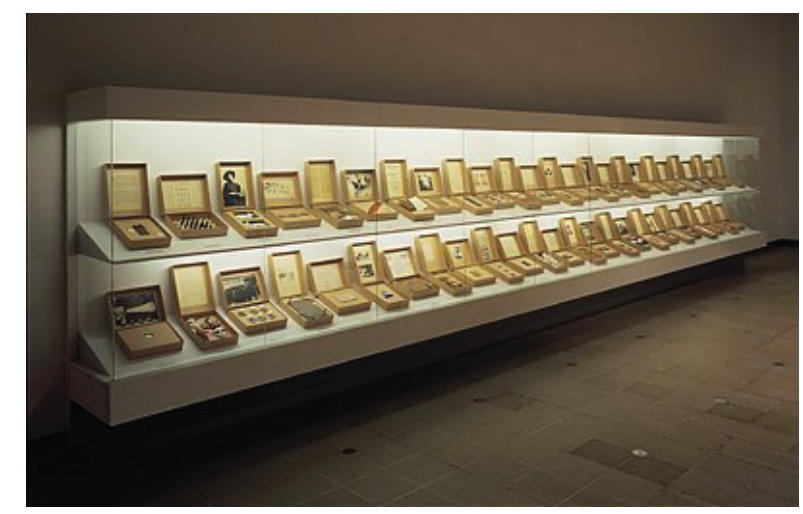

Ilust. 9. Susan Hiller, From the Freud Museum (do museu de Freud) 1991-97

Aqui o arquivo pessoal ganha o espaço público do museu, assumindo um caráter antropológico, ampliando os complexos níveis de uma memória individual, que é necessariamente constituída de dimensões históricas, políticas, sociais, culturais e subjetivas. Feita especialmente para o museu de Freud, o pai da psicanálise, os objetos adquirem naquele contexto um potencial de expandir seus possíveis significados, evidenciando a possibilidade de se ler o inconsciente de uma cultura, aquilo que estaria reprimido, não explícito no arquivo, mas latente no mesmo, aguardando para ser desvendado.

Hiller conta que, ao visitar o museu, ficou impressionada com a rica coleção de Freud de arte e artefatos clássicos e etnográficos, e resolveu criar sua própria coleção de mementos culturais: "são artefatos e materiais sem valor algum - lixo, fragmentos descartados, coisas triviais, reproduções - mas que pareciam carregar uma aura de memória e apontar para algum significado" (Hiller, 2000). O trabalho de Hiller reflete a metáfora arqueológica de Freud, em relação à psicanálise, escavando arquivos reprimidos nas profundezas do inconsciente, para encontrar seu significado, um processo também do comum ao fazer artístico.

\subsection{Arquivos cidatinos: Nara Milioli e asikainen\&macêdo}

O registro fotográfico em andamento da ocupação do Morro do Horácio (2003-

${ }^{4}$ Susan Hiller, disponível em: http://www.eaf.asn.au/hillerweb/SHE3.html; acesso em 06/12/2009. 
2007), localizado no Bairro Agronômica em Florianópolis, o qual vem sendo realizado pela artista Nara Milioli, está gerando um arquivo que acompanha o crescimento urbano informal desta área. O projeto, iniciado em 2003, justapõe imagens do mesmo local, fotografadas num intervalo de aproximadamente dois anos, revelando as transformações ocorridas na paisagem neste curto período.

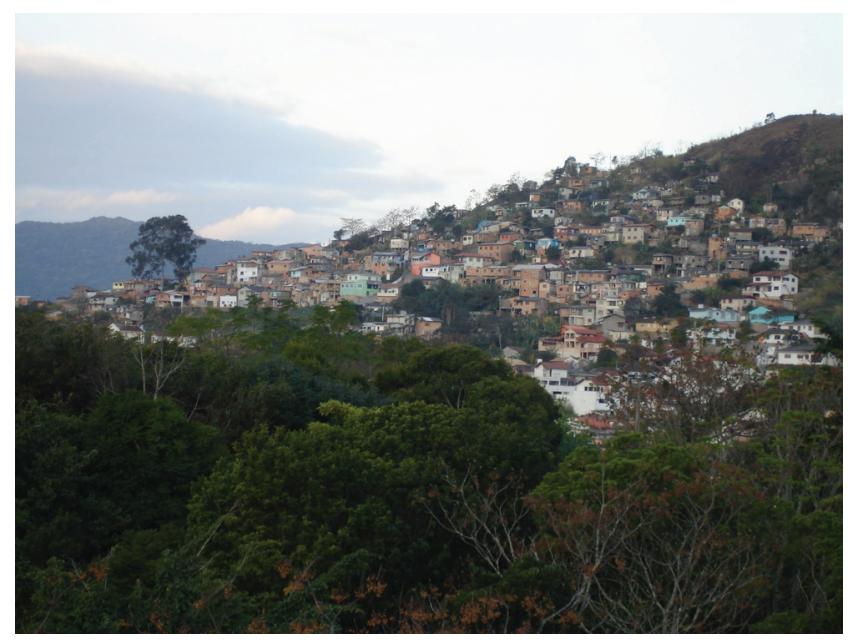

Ilust. 10. Nara Milioli, Morro do Horácio, 2003

Segundo Nara Milioli, "o trabalho aponta para a ocupação desordenada e contínua do morro pelas pessoas, ao mesmo tempo em que revela o aspecto acolhedor das casas, como ninhos ou abrigos". ${ }^{5}$ Este trabalho foi pensado para ser apresentado em dois suportes, uma fotografia $(20 \times 30 \mathrm{~cm})$ e cartões postais $(10 \times 15 \mathrm{~cm})$. Nara Milioli pesquisou em sua tese de Doutorado em Poéticas Visuais na Escola de Comunicação e Artes da USP, os conceitos acerca da paisagem e do corpo, bem como as inter-relações entre esses conceitos, as oscilações no corpo da paisagem e do corpo na paisagem.

Mais recentemente, Nara criou um segundo anti-postal, como ela denomina estas series fotográficas de vistas não turísticas de Florianópolis, intitulado Via expressa, 2006. Este trabalho consiste de uma fotografia de um morro habitado, exposta em um outdoor posicionado em frente ao morro.

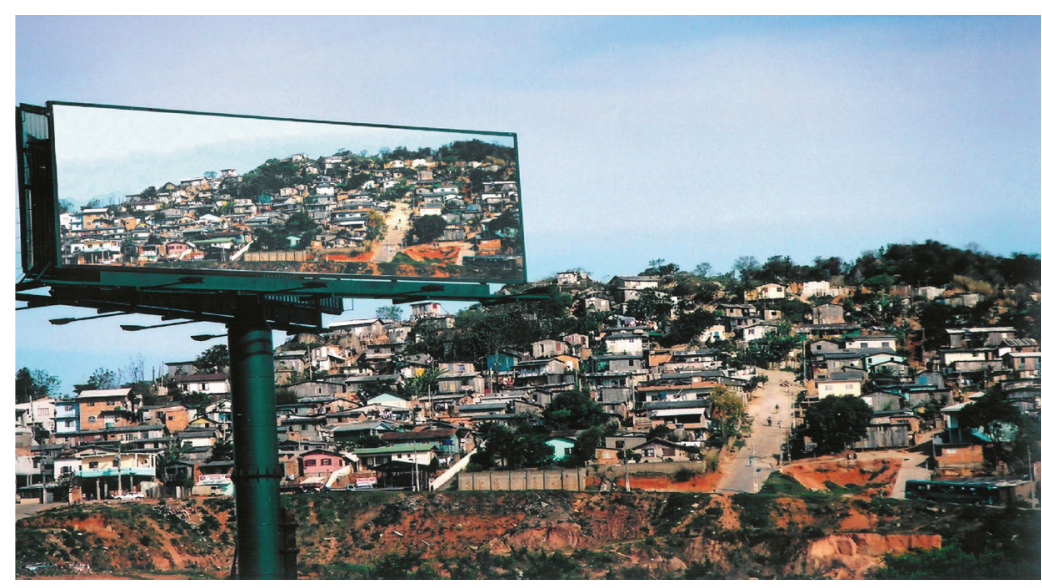

Ilust. 11. Nara Milioli, Via Expressa, 2006

5 Texto não publicado para proposta de exposição para a Fundação Cultural BADESC, 2008. 
Estes trabalhos de Nara subvertem o gênero cartão-postal, tradicionalmente um instrumento de propaganda efetivo na construção da imagem oficial da cidade. O poder que esta imagem fotográfica adquire neste contexto é a meu ver monumental. O espaço do out-door funciona como uma tela de ilusões na qual se desenrolam imagens da sociedade espetacular, com seus sedutores objetos de desejo, promessas de felicidade e plenitude. É precisamente nesta mesma superfície que a imagem de Nara cria uma fissura pela qual emerge o real interrompendo o fluxo do espetáculo, como um grande ruído silencioso. Ao olhar este projeto, senti como se o tempo tivesse parado por alguns instantes para podermos contemplar o óbvio.

Ao confrontar a imagem do morro da via expressa com sua imagem ampliada num out-door, o trabalho funciona como um espelho gigante do qual emerge uma memória reprimida, que escapa como um ato falho do inconsciente da cidade. Um arquivo obsessivamente recalcado, suprimido pelas autoridades municipais. Sente-se aqui novamente o efeito de um mal de arquivo, o desejo de se esquecer, de apagar imagens que jamais fariam parte da imagem oficial do paraíso balneário, mas que insistem em emergir.

Também como parte de um projeto de pensar o espaço urbano, uma série de fotografias de asikainen\&macêdo foram feitas na cidade de Newcastle, no Reino Unido, como parte de um evento que ocorreu em 2002, intitulado Capital. Artistas participantes realizaram projetos em torno da temática urbana.

Esta instalação fotográfica consistiu de seis fotografias e a seguinte citação de um texto de Michel Serres pintado numa parede:

Vivemos dentro das muralhas de nossas cidades ou sob a abóboda estrelada? Em qual dos dois?

Habitamos mais do que o outro?

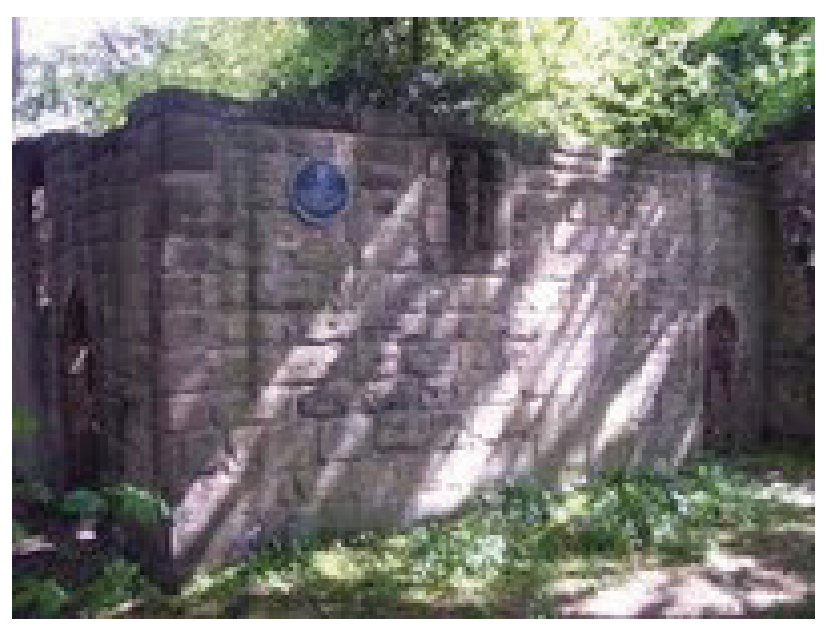

Ilust. 12. Saint Mary Chapel, Newcastle, 2002

As imagens formam um pequeno arquivo originado a partir de uma visita a um sítio histórico de Newcastle, as ruínas da capela Saint Mary do século XII. Nos in- 
trigou o uso atual deste espaço pela vizinhança, que o transformou em um tipo de santuário particular, trazendo para as ruínas flores, velas entre outras oferendas. Narrativas contemporâneas foram adicionadas à dimensão histórica e arqueológica do lugar.

Este trabalho aborda estas manifestações no local com uma pergunta. Como se pode compreender a fé e a espiritualidade? Seria possível apreender a intensidade psicológica de atos devocionais espontâneos através de meios racionais? O tratamento dado aos objetos remete a uma estratégia científica usada por arqueólogos, que apresentam ao observador objetos ou artefatos encontrados em santuários de uma maneira "neutra" ou não religiosa, resultando num pequeno arquivo de imagens.

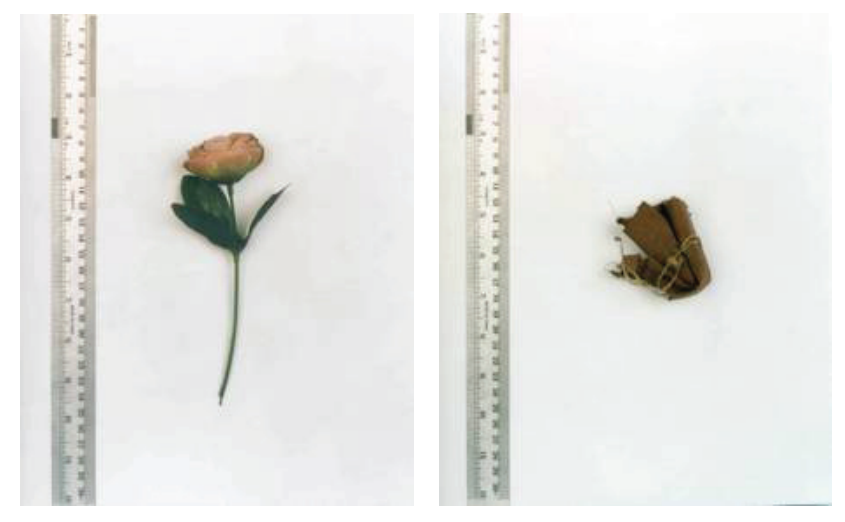

Ilust. 13 e 14. asikainen\&macêdo, da série sem titulo (Saint Mary Chapel), 2002

As trocas com o mundo do além às vezes se dão por meios surpreendentemente mundanos, como as oferendas em dinheiro. Mas talvez este seja apenas um aspecto das formas mais complexas e misteriosas que as pessoas usam para expressar suas esperanças e buscar alívio para seus sofrimentos existenciais.

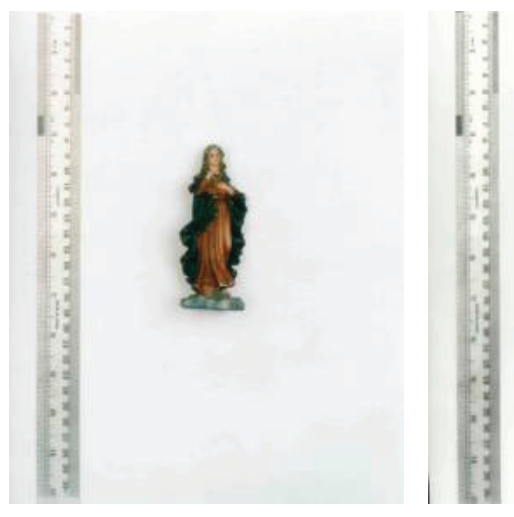

Ilust. 15 e 16. asikainen\&macêdo, da série sem titulo (Saint Mary Chapel), 2002

A formação de um pequeno arquivo fotográfico destas manifestações populares nas ruínas da capela lida com a questão da memória de um espaço urbano em constante transformação. O arquivo aqui busca registrar a camada mais superficial deste incessante adensamento de significados que se associam a este lugar ao longo dos séculos. 


\section{Referências Bibliográficas:}

DERRIDA, Jacques. Mal de Arquivo: uma impressão freudiana. Rio de Janeiro: Relume Dumará, 2001.

ENWEZOR, Okwui. Archive Fever: uses of the document in contemporary art. New York: International Center of Photography; Gottingen: Steidl Publishers, 2008. FOSTER, Hal. An Archival Impulse. October 110 (Fall 2004). Princeton: MIT Press, 2004.

HILLER, Susan. After the Freud Museum. Londres: Book Works, 2000. Catálogo também disponível em: http://www.freud.org.uk/exhibitions/10535/afterthe-freud-museum/ e em: http://www.moma.org/interactives/exhibitions/1999/ muse/artist_pages/hiller_freudmuseum.html

RENNÓ, Rosângela. Rosengela Rennó. São Paulo: Editora da Universidade de São Paulo, 1998.

\section{Title:}

Archive fever: the archive dynamics in contemporary art

\section{Abstract:}

The aim of this text is to explore the impact of the idea of archive in contemporary art. In "Archive Fever" Jacques Derrida explores the double sense of the etymological root of the word archive, which means both origin and command or power of an authority. As the notion of archive is directly related to memory, personal and historical, the author reveals the relation of archive and power, arguing that there is a constant tension between maintenance and repression (conscious or unconscious) of memory. The archive fever would be associated with the death drive, loss of memory, which would have psychic, social and political consequences. Taking on account this approach, the idea of archive is identified as a central procedure in contemporary art practice. Many artists develop projects around notions of falsification of archives; appropriate and manipulate historical archive material; or use scientific methodology in their poetical processes, creating fictional archives and strange taxonomies.

\section{Keywords:}

Archive; contemporary art; memory; photography; Derrida 